\title{
Variation of ozone and PBL from the lidar observations and WRF-Chem model in NYC area during the 2018 summer LISTOS campaign
}

\author{
Kaihui Zhao ${ }^{1 *}$, Yonghua $\mathrm{Wu}^{2,3}$, Jianping Huang ${ }^{4}$, Rongsheng Jiang ${ }^{5}$, Guillaume Gronoff ${ }^{6}$, \\ Timothy A. Berkoff ${ }^{6}$, Fred Moshary ${ }^{2,3}$ \\ ${ }^{1}$ Yale-NUIST Center on Atmospheric Environment, Nanjing Univ. of Information Science \& Technology, \\ China.*Email: 645746215@qq.com \\ ${ }^{2}$ the City College of New York (CCNY), New York, NY 10031, USA. \\ ${ }^{3}$ NOAA-Cooperative Science Center for Earth System Sciences and Remote Sensing Technologies \\ ${ }^{4}$ NOAA-NCEP Environmental Modeling Center and IM System Group Inc., College Park, MD 20740, USA \\ ${ }^{5}$ School of Atmospheric Sciences, Nanjing University of Information Science and Technology, China \\ ${ }^{6}$ NASA Langley Research Center, Hampton, VA 23681, USA
}

\begin{abstract}
High ozone $\left(\mathrm{O}_{3}\right)$ episodes frequently occur in New York metropolitan and the downwind coastal area in summer. In this study, lidar/ceilometer are combined with WRF/Chem model to investigate an $\mathrm{O}_{3}$ event on Aug. 27 30 2018. We examine the spatial-temporal variabilities of $\mathrm{O}_{3}$ and planetary-boundary-layer height (PBLH) and assess the model performance on simulating surface $\mathrm{O}_{3}$ during this episode. By comparing with the lidar observations, the WRF/Chem is able to capture high $\mathrm{O}_{3}$ distribution in the PBL at noon and indicates consistent diurnal evolution for the ground $\mathrm{O}_{3}$. Nevertheless, in the early morning and night, the model overestimates the ground $\mathrm{O}_{3}$ and underestimates the PBLH.
\end{abstract}

\section{INTRODUCTION}

Surface ozone is a secondary pollutant formed by a series of photochemical reactions involving oxides of nitrogen $\left(\mathrm{NO}_{\mathrm{x}}=\mathrm{NO}+\mathrm{NO}_{2}\right)$ and volatile organic compounds (VOCs) in the presence of solar ultraviolet radiation. Lidar and numerical models are powerful tools for understanding the mechanisms for the regional transport and local chemical reactions compared with the routine surface measurements [1]. The coastal areas in the northeast US and mid-Atlantic ocean are still suffering from high $\mathrm{O}_{3}$ in summer through various processes, such as downwind transport from urban area [2], local photochemical production of $\mathrm{O}_{3}$ and recirculation brought about by sea breeze [3]. However, most of the modeling studies of ozone exceedance at the coastal areas were limited to the regional chemistry models with relatively coarse resolution of land-use data, which may pose a large uncertainty to the $\mathrm{O}_{3}$ forecast.

New York City is situated in the northeastern US with an estimated population more than 8 million distributed over a land area of about 784 $\mathrm{km}^{2}$. Summer $\mathrm{O}_{3}$ exceedances of US-EPA National Ambient Air Quality Standard (NAAQS) are often observed in the urban and coastal areas. Thus, it is important to investigate the formation mechanisms of high $\mathrm{O}_{3}$ events and evaluate the model forecast skills. In this study, an ozone lidar and a ceilometer are used to characterize diurnal vertical distribution of ozone and PBLH on 27-30 August 2018 in 
$\mathrm{NYC}$ area. The ranged-resolved $\mathrm{O}_{3}$ and PBLHs are focused to investigate the formation mechanisms of $\mathrm{O}_{3}$ during a heat-wave event.

\section{METHODOLOGY}

\subsection{Model and configurations}

The version 3.7.1 of the WRF/Chem model was used in this study [4]. The grid point dimensions from the outermost to the innermost domains are $85 \times 75,76 \times 70$, and $70 \times 61$ with horizontal resolutions of $12 \mathrm{~km}, 4 \mathrm{~km}$ and $1.3 \mathrm{~km}$, respectively. Outputs from the whole atmosphere community climate model (WACCM) provide initial and lateral conditions of chemical species to drive the WRF/Chem simulations.

The details for the model application to NYC area can be seen in [5].

\subsection{Observational data}

Two ceilometers (Vaisala CL-51 \& CL-31) make the PBLH measurements at CCNY campus $\left(40.821^{\circ} \mathrm{N}, 74.0^{\circ} \mathrm{W}\right)$ and Eatons Neck (coastal site, $40.93^{\circ} \mathrm{N}, 73.40^{\circ} \mathrm{W}$ ), respectively [6]. The NASA-Langley mobile ozone lidar is operated for range-resolved ozone profiles at Westport site, CT $\left(41.07^{\circ} \mathrm{N}, 73.2^{\circ} \mathrm{W}\right)$. The details of the lidar specifications and measurement analysis can be seen in [7-8]. In addition, the measurements of ground-level $\mathrm{O}_{3}$ and other species are operated by the NYSDEC (New York State Department of Environment Conservation). The hourly mean raw data were used to validate the model predictions. Further, both surface meteorological and sounding data were used to evaluate the model performance on simulating meteorological variables. Vertical profiles of temperature, relative humidity and wind speed measured at Upton site (OKX, $40.87^{\circ} \mathrm{N},-72.86^{\circ} \mathrm{E}, 20 \mathrm{~m}$ above sea level) and are utilized to assess the simulated vertical profiles.

\section{RESULTS and DISCUSSION 3.1 $\mathrm{O}_{3}$ spatial-temporal variations}

Figure 1 shows the spatial distribution of WRF-Chem-simulated surface $\mathrm{O}_{3}$ at 14:00 EST
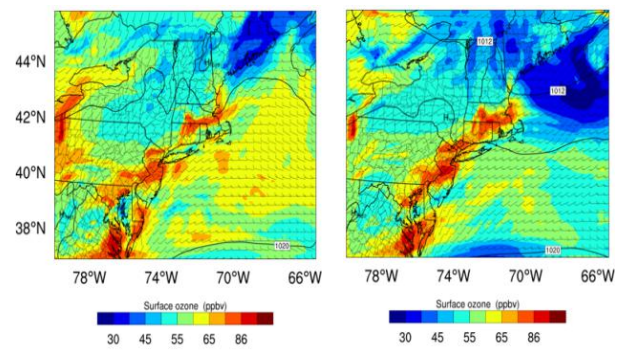

Fig.1 Surface $\mathrm{O}_{3}$ by WRF/Chem model (shaded colors) and wind (black barb) at 14:00 EST on (left) Aug. 28, (right) Aug. 29, 2018
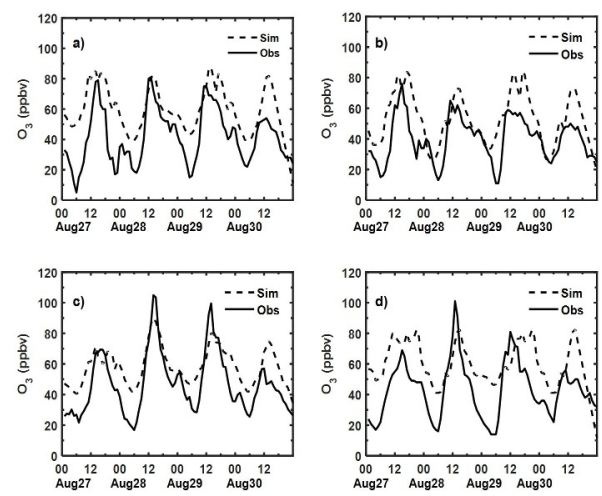

Fig.2 Simulated (dashed:) and observed (solid) surface $\mathrm{O}_{3}$ at a) Queens College, b) CCNY (urban), c) Eatons Neck (coastal), and d) Babylon.

on Aug. 28 and 29, 2018, respectively. High $\mathrm{O}_{3}$ can be seen in the NYC and the coastal area, along with the prevailing southwest winds. Figure 2 illustrates the time series of surface $\mathrm{O}_{3}$ during 27-30 August 2018 at NYC urban and Long Island stations. The model captured the diurnal variations, the daily $\mathrm{O}_{3}$ peak values, and an increasing trend at different sites quite well except Aug. 30, but surface $\mathrm{O}_{3}$ concentrations are over-predicted in the morning and night time. With favorable meteorological conditions for $\mathrm{O}_{3}$ formation, the hourly maximum ozone higher than 70-100 ppb was observed in the NYC and 
surrounding regions, leading to violation of the (NAAQS) for surface $\mathrm{O}_{3}$ (70-ppb for daily maximum of 8hr-ave). On August 30, the $\mathrm{O}_{3}$ concentration decreased a little due to the effect of cloud. In addition, the nighttime over-prediction of $\mathrm{O}_{3}$ is probably attributed to the underpredicted PBLH and underestimated NO concentration.

Figure 3 (a) and (c) illustrate the spatial and temporal distribution of $\mathrm{O}_{3}$ mixing ratio measured with the NASA Langley $\mathrm{O}_{3}$ lidar at Westport on 28-29 August 2018. The model results are shown in Fig.3 (b) and (d) for comparison. The $\mathrm{WRF} / \mathrm{Chem}$ is able to reproduce the ozone diurnal variations and the $\mathrm{O}_{3}$ structure in the PBL. On 28 August, $\mathrm{O}_{3}$ concentration higher than $100-p p b v$ was observed at 20:00 UTC and extended to $1 \mathrm{~km}$ height in the PBL. One day later, the hourly-average maximum $\mathrm{O}_{3}$ was reduced to about 80.0 ppbv. Meanwhile, a layer with $\mathrm{O}_{3}$ concentration lower than $50.0 \mathrm{ppbv}$ maintains at the height of $1-\mathrm{km}$ above ground level during these two days. The vertical distribution of ozone indicates that the local emissions and chemical production play a critical role in the exceedance of NAAQS for $\mathrm{O}_{3}$.

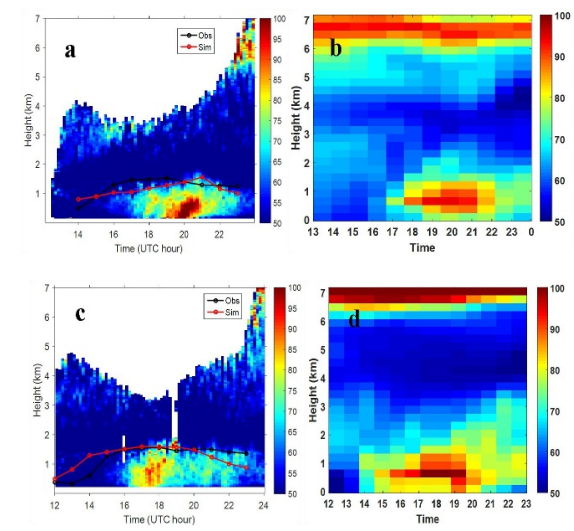

Fig. 3 Spatial and temporal distribution of $\mathrm{O}_{3}$ mixing ratio (ppbv) at Westport (red line: simulated PBL height; black line: observed PBL height at CCNY on 28, 29 August 2018 (a and c: ozone lidar; b and d: WRF/Chem model) (UTC-4=local time)

\subsection{PBL and meteorological profiles}

Figure 4 shows the spatial and temporal variations of simulated (boundary layer height) PBLH and the ceilometer observation at Eatons Neck, a coastal site in Long Island Sound. The model shows higher PBLH in the land but much lower in the Long Island sound and marine area at 19:00 UTC (local noon time) Aug.29, 2018. Such large differences in the land and costal/marine area need to be validated from the observations. Near the coastal region, the simulated maximum PBLHs shows better agreement with the ceilometer observation, but the PBL development time was about 2-3 hours earlier than the observation and the PBLH is over-estimated during 8:00-12:00 UTC (UTC-4=local time, 4:00-8:00 early morning). The over-predictions of the PBL height could be due to the uncertainties of the PBL schemes and surfaces.
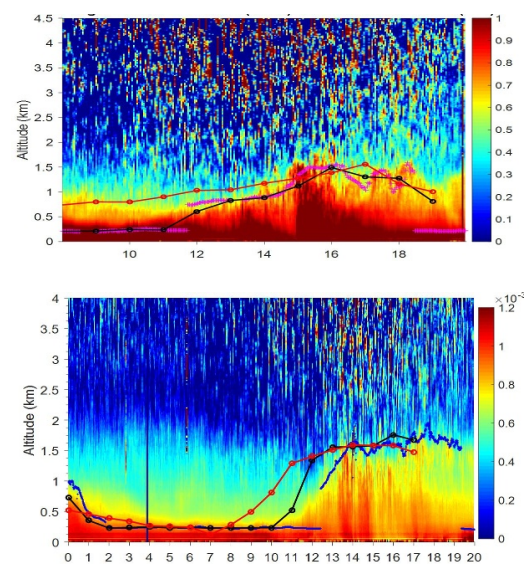

Fig 4. PBLH spatial distribution at 19:00 UTC on Aug. 29 by WRF-Chem model; ceilometer observation at Eatons Neck (coastal site) on Aug. 28 (top) and 29 (bottom). (red line: model; black: obs.; pink: 2-min ave for the obs. PBLH)

Figure 5 shows simulation-observation comparisons of vertical profiles of potential temperature, relative humidity, and wind speed in the morning (08:00 EDT) during 27-30 August 2018. Overall, the simulated vertical 
profiles agree well with the observations. The potential temperature significantly increased and the slope under $1 \mathrm{~km}$ became more stable during this event (figure5). The relative humidity obviously increased above $1-\mathrm{km}$ which is consistent with the low ozone concentration layer. In contrast, the simulated wind profiles did not agree well with observations due to the complex topography. The wind speeds were persistently weak during this event. The lower wind speed is favorable for ozone photochemical accumulation of ozone and its precursors.
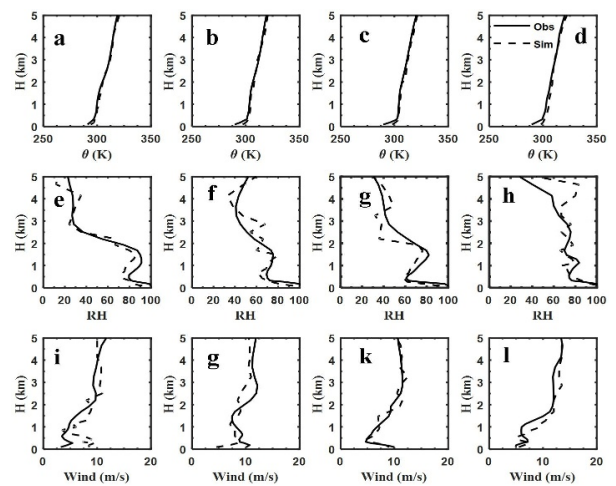

Fig.5 Comparison of WRF/Chem-simulated vertical profiles with radiosonde observed potential temperature, relative humidity $(\mathrm{RH} \%)$, wind speed at 08:00 EDT, OKX Upton during the event (panels a), e) and i) for Aug. 27; b), f), and j) for Aug. 28; and c), g) and k) for Aug.29; d), h), 1) for Aug. 30.

\section{CONCLUSION}

This extended abstract presents a case study of ozone exceedance event in NYC urban and its coastal area on August 27-30, 2018 with WRF/Chem simulations and observational data. The maximum hourly-averaged ozone concentrations higher than 70-100 ppb were observed at both the urban and rural or coastal areas. The diurnal variation of surface ozone, PBLH and ozone vertical distribution were well captured by the WRF/Chem model. The vertical distribution of ozone indicates that the local emissions and chemical production play a critical role in the exceedance event of NAAQS of $\mathrm{O}_{3}$. The model was successful in reproducing the maximum PBLHs but the PBL development time with 2-3 hours earlier than the observations near the coastal areas.

\section{ACKNOWLEDGEMENTS.}

The New York State Energy Research and Development Authority (grant \# 100415 and 137482), NESCAUM (grant \# 2411) and the NOAA-Cooperative Science Center for Earth System Sciences and Remote Sensing Technologies under the Cooperative Agreement Grant \#NA16SEC4810008, the National Science Foundation of China (Grant 41575009), the Xianyang major science and technology projects (2017YFC0210102) support this study.

\section{REFERENCES}

[1] Chaxel E, et al., 2009: Ozone production from Grenoble city during the August 2003 heat wave. Atmos. Environ., 43(31):4784-4792.

[2] Angevine, W.M., et al., 2004: Coastal Boundary Layer Influence on Pollutant Transport in New England. J. Appl. Meteor., 43, 1425-1437.

[3] Banta, R M, et al., 2005: A Bad Air Day in Houston. Bull. Amer. Meteor. Soc., 86(5):657-669.

[4] Grell, G. A., et al., 2005: Fully coupled "online” chemistry within the WRF model, Atmos. Environ., 39, 6957-6975.

[5] Zhao, K., et al., 2019: A high-resolution modeling study of a heat wave-driven ozone exceedance event in New York City and surrounding regions, Atmos. Environ., 199, 368-379.

[6] Gan, C. M., et al., 2010: Statistical comparison between hysplit sounding and lidar observation of planetary boundary layer characteristics over New York City, SPIE Proc., vol. 7684-57

[7] Young, R. D. et al. 2017: Langley mobile ozone lidar: ozone and aerosol atmospheric profiling for air quality research, Appl. Opt. 56, 721-730.

[8] Farris, B. Met al., 2019: Demonstration of an off-axis parabolic receiver for near-range retrieval of lidar ozone profiles, Atmos. Meas. Tech., 12, 363-370. 